\title{
THE BOSTON CARPAL TUNNEL QUESTIONNAIRE /BCTQ/ - A RELIABLE METHOD FOR DIAGNOSIS AND ASSESSMENT OF THE TREATMENT OF CARPAL TUNNEL SYNDROME
}

\author{
Vladeva E. P., MD, PhD, Medical University, Varna, Bulgaria \\ Department of Physiotherapy, Rehabilitation, Thalassotherapy and Occupational Diseases
}

DOI: https://doi.org/10.31435/rsglobal_wos/28022020/6920

\begin{tabular}{l} 
ARTICLE INFO \\
Received: 13 December 2019 \\
Accepted: 17 February 2020 \\
Published: 28 February 2020 \\
\hline
\end{tabular}

\section{KEYWORDS}

carpal tunnel syndrome,

Boston Carpal Tunnel Questionnaire (BCTQ),

physiotherapeutic treatment.

\section{ABSTRACT}

CTS is the most common compression neuropathy with an incidence of $125-515 / 100000$. It is a result of compression of the median nerve by the transverse carpal ligament. It is observed in 2 to $5 \%$ of the general population, more frequently in women.

In the last few years the scientific society has acknowledged the Boston Carpal Tunnel Syndrome Questionnaire (BCTQ) and more and more frequently it is being used as a standard in CTS patients. The literature also contains numerous studies on the diagnostics and treatment of CTS using BCTQ.

Aim of study. To investigate the effect of a complex of physical factors on the reverse development of symptoms of moderate carpal tunnel syndrome using BCTQ and to compare the results of the BCTQ subjective rating (SSS) (symptom severity scale) and function - FSS (functional status scale) with objective assessment measured by the ENG parameters of $n$. medianus Materials and methods. 57 patients with mild to moderate degree of carpal tunnel syndrome clinically proven by electroneurographic study were examined. $38.60 \%$ of the patients were with right hand affected, 9 patients $(15.80 \%)$ with left hand affected and 26 patients $(45.60 \%)$ with bilateral involvement $(n=26)$, In the last group, we examined both hands, i.e. 57 patients and 82 hands were investigated.

Based on the analysis of our own studies, we applied the following complex physiotherapeutic program to the patients involved in the study: ultrasound, electrophoresis with Nivalin (Galantamine), and traditional kinesitherapy program.

Results and discussion. By analyzing the results of the symptom severity assessment of the first part of the questionnaire we find that subjective complaints of patients decreased statistically significantly at the end of physiotherapy course from an average of 2.67 before treatment to 2.21 at the end of FTP $(p<0.01)$. This trend continues within $1-4$ months after the end of physiotherapy - average 1.79 and maintains up to $4-8$ months when the mean of the results is 1.69 ( $p<0.001)$. We found that with regard to the recovery of the function of the affected hand and the way it affects some of the activities of daily living, the results of the second part of the BCTQ - functional status scale - show a statistically significant improvement at the end of the physiotherapy course 1.91 to an average of 1.63 ( $\mathrm{p}<0.001$ ), with a tendency for long-term retention and a slight decrease in the average of the results obtained to 1.37 within the first control examination at $1-4$ months $(\mathrm{p}<0.001)$ and resistance to this trend in the following months $(4-8)-1.31$ ( $\mathrm{p}<0.001)$.

Based on the ANOVA analysis and the calculation of the $\eta$ coefficient, we proved that there is no significant difference in the results obtained from the Boston questionnaire and those from the ENG examination. There is a high percentage of overlap - from $53.10 \%$ to $95.60 \%$.

Although the results of the questionnaire are based on the subjective assessment of the patient, there is a high percentage of overlap with those of the objective study (ENG), which is a prerequisite for assuming that the questionnaire is highly reliable and valid and can be used as a tool for evaluating and analyzing a number of CT C studies, which is in line with Leite's findings that the Boston Questionnaire is highly reliable and can replace any other non-standard methods for assessing CTS severity 


\begin{abstract}
Conclusions. In the presented facts of the discussion impression makes the patient's influence both on the subjective complaints and the clinical symptoms as well as on the degree of restoration of the affected hand functions at the end of the physiotherapy course, the continuation of this trend up to 4 months after the end of the treatment and maintaining it for 4 to 8 months.

Although the results of BCTQ are based on the subjective assessment of the patient, there is a high percentage of overlap with those of the objective study (ENG), which is a prerequisite for assuming that the questionnaire is highly reliable and valid and can be used as a tool for evaluating and analyzing a number of carpal tunnel studies, which is in line with Leite's findings that the Boston Questionnaire is highly reliable and can replace any other non-standard methods for assessing CTS severity
\end{abstract}

Citation: Vladeva E. P. (2020) The Boston Carpal Tunnel Questionnaire /BCTQ/ - a Reliable Method for Diagnosis and Assessment of the Treatment of Carpal Tunnel Syndrome. International Academy Journal Web of Scholar. 2(44). doi: 10.31435/rsglobal_wos/28022020/6920

Copyright: (C) 2020 Vladeva E. P. This is an open-access article distributed under the terms of the Creative Commons Attribution License (CC BY). The use, distribution or reproduction in other forums is permitted, provided the original author(s) or licensor are credited and that the original publication in this journal is cited, in accordance with accepted academic practice. No use, distribution or reproduction is permitted which does not comply with these terms.

Introduction. Compression neuropathies are focal lesions of the peripheral nerves with a different etiology and are caused by narrowing or mechanical stretching of the nerve root in a fibrous or fibrous bone canal, or by fibrous tissue. They are characterized by pain, sensory impairment and/or loss of function as a result of chronic pressure (compression) [1].

CTS is the most common compression neuropathy with an incidence of $125-515 / 100000$. It is a result of compression of the median nerve by the transverse carpal ligament. It is observed in 2 to $5 \%$ of the general population, more frequently in women. It is considered that there is a link between this condition and the occupational load on the wrist when working on a keyboard, in the presence vibrations, in cases of overexertion of the upper limbs, etc.

In the last few years the scientific society has acknowledged the Boston Carpal Tunnel Syndrome Questionnaire (BCTQ) and more and more frequently it is being used as a standard in CTS patients. [2] The scientific literature contains a large number of analyses and comparative studies focused on the reliability of this questionnaire. Most of them consider it more reliable when diagnosing CTS and determining its severity than any other similar instrument. The literature also contains numerous studies on the diagnostics and treatment of CTS using BCTQ. According to many authors its use is almost obligatory in the field of CTS. The advantage of this questionnaire is that it analyses the symptoms related to sensation (pain, loss of sensation, etc.) and the degree of functional preservation of the hand in CTS patients, providing two types of data: on 'clinical symptoms' - SSS (severity status scale) and on 'function' - FSS (functional status scale).[3, 4]

According to Leite, BCTQ has proven to have high reliability and can replace all other nonstandardized methods for the assessment of CTS severity.

Aim of study. To investigate the effect of a complex of physical factors on the reverse development of symptoms of moderate carpal tunnel syndrome using BCTQ and to compare the results of the BCTQ subjective rating (SSS) (symptom severity scale) and function - FSS (functional status scale) with objective assessment measured by the ENG parameters of n. medianus

Materials and methods. 57 patients with mild to moderate degree of carpal tunnel syndrome clinically proven by electroneurographic study were examined. $38.60 \%$ of the patients were with right hand affected, 9 patients (15.80\%) with left hand affected and 26 patients (45.60\%) with bilateral involvement $(n=26)$. In the last group, we examined both hands, so 57 patients and 82 hands were investigated (Fig. 1). 


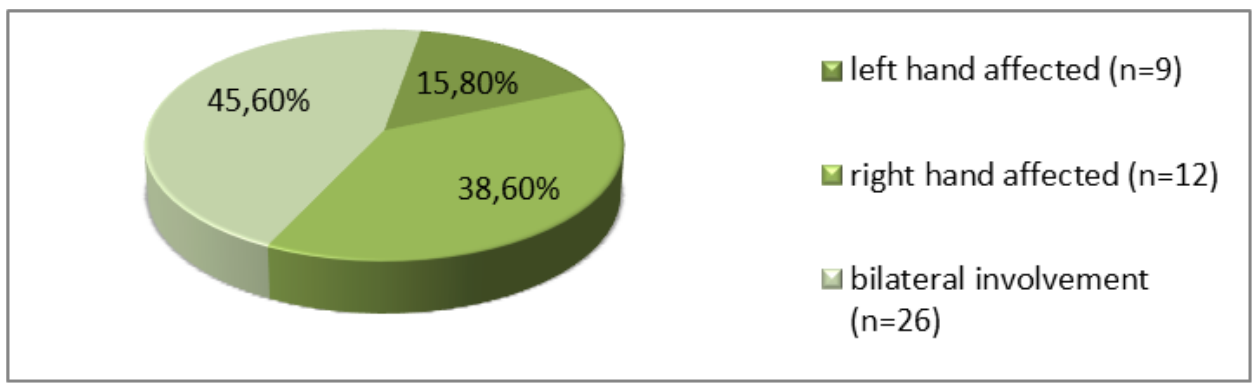

Fig. 1. Relative share of the affected hand in patients with CTS.

\section{Criteria for inclusion:}

$>$ Persons over 18 years old;

$>$ Persons with mild to moderate CTS, according to electrophysiological standards of the Association of Clinical Electromyography and Evoked Potentials of ENG Research;

Persons who have not undergone surgical treatment;

Based on the analysis of our own studies, we applied the following complex physiotherapeutic program to the patients involved in the study:

- Ultrasound / 3-4 min / locally in the projection of the carpal tunnel at a rate of $0.2-0.3 \mathrm{w} /$ $\mathrm{cm} 2$ with a view hydrolytically, anti-inflammatory and antiedematous action of ultrasound, and in order to improve the effect of subsequent electrophoresis because thermal and the mechanical effect of $\mathrm{KH}$ proved to improve the absorption capacity of the skin (Bussarov, 1968)

- Electrophoresis with Nivalin (Galantamine) (+) locally, with the positive electrode located in the carpal canal projection of 10 to 18 minutes and a current of $6-16 \mathrm{~mA}$ in order to improve the nerve conductivity

- Traditional kinesitherapy program including analytical exercises, facilitating techniques, massage, soft-tissue mobilization, muscle relaxation and stretching techniques, joint mobilization techniques, active musculoskeletal exercises to strengthen forearm and arm muscles and training precision gauges and reeducation of sensation.

\section{Results and discussion.}

Evaluation of the effect of physiotherapy treatment on reversal of symptoms and improvement of function of the affected hand by BCTQ.

By analyzing the results of the symptom severity assessment of the first part of the questionnaire - symptom severity scale, which refers to the type and severity of subjective complaints, the frequency and time of day they occur, we find that subjective complaints of patients decreased statistically significantly at the end of physiotherapy course from an average of 2.67 before treatment to 2.21 at the end of physiotherapy treatment ( $p<0.01$ ). This trend continues within $1-4$ months after the end of treatment - average 1.79 and maintains up to $4-8$ months when the mean of the results is 1.69 (p <0.001) (Fig. 2).

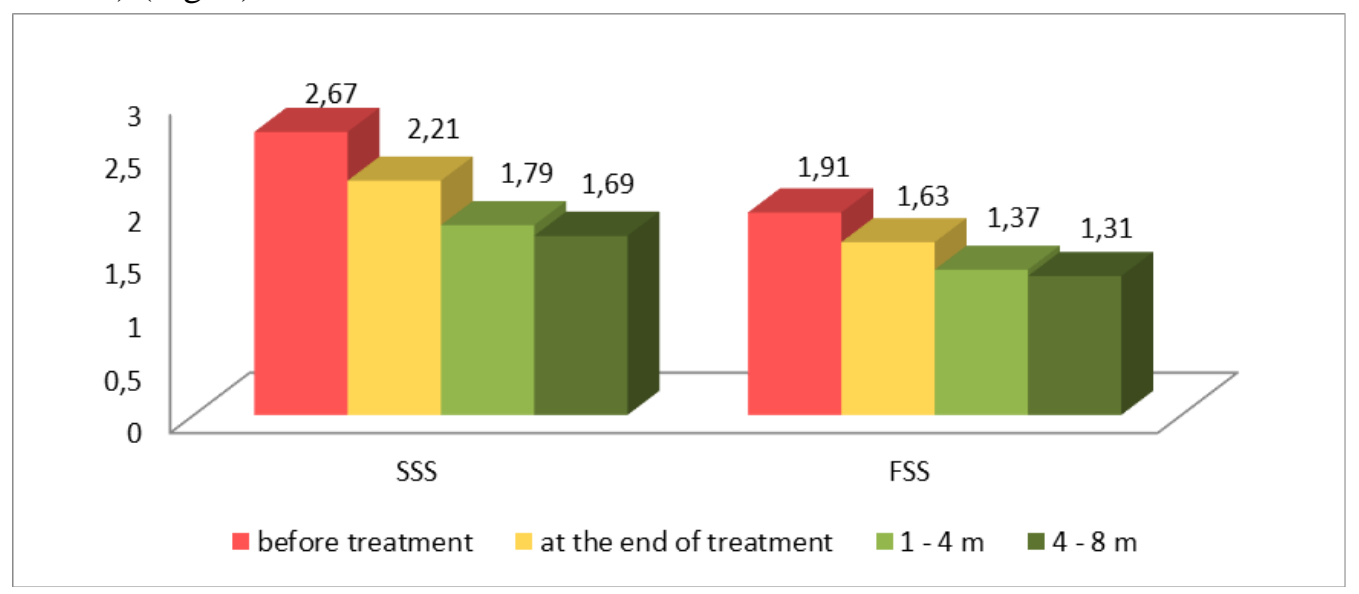

Fig. 2. Average BCTQ score, before and after treatment

We found that with regard to the recovery of the function of the affected hand and the way it affects some of the activities of daily living, the results of the second part of the BCTQ - functional 
status scale - show a statistically significant improvement at the end of the physiotherapy course 1.91 to an average of 1.63 ( $\mathrm{p}<0.001$ ), with a tendency for long-term retention and a slight decrease in the average of the results obtained to 1.37 within the first control examination at $1-4$ months ( $<<0.001$ ) and resistance to this trend in the following months (4-8) - 1.31 (p <0.001). (Fig. 2). The results presented in Fig. 2 show that in the patients we studied, the degree of involvement with respect to subjective complaints - stiffness, pain, paresthesias was higher than the degree of involvement of the function of the affected hand and daily activities.

Comparison of the results of the BCTQ subjective assessment and the objective evaluation measured by the n. medianus ENG parameters

We compared the severity scores of the symptoms of SSS and FSS of the Boston Questionnaire with those obtained from ENG examination of sensory and motor fibers.

The results of the ANOVA analysis and the calculation of the $\eta$ coefficient presented in Table 1 show that the overlap between SSS and distant latency of sensory fibers ranged from $53.10 \%$ to $72.10 \%$ in the period prior to initiation of treatment to 1-4 and 4-8 months after the start of treatment. Even higher is the percentage of overlap when comparing the results of SSS and those for SNAP-sensory fibers from ENG - from $84.30 \%$ to $91.50 \%$ for the same period. When comparing the results between SSS and conduction velocity on sensory ENG fibers, this percentage ranges from $84.30 \%$ to $89.80 \%$.

Table 1. Comparison of the results of the BCTQ subjective assessment (symptom severity scale) and the objective assessment measured by the ENG parameters of $n$. medianus.

\begin{tabular}{|c|c|c|c|}
\hline BCTQ & ENG-parameters of $n$. medianus & $\begin{array}{c}\text { Stage of } \\
\text { investigation }\end{array}$ & $\begin{array}{c}\% \text { of BCTQ and ENG } \\
\text { overlap }\end{array}$ \\
\hline \multirow{9}{*}{$\begin{array}{l}\text { SSS } \\
\text { (symptom } \\
\text { severity scale) }\end{array}$} & \multirow{3}{*}{$\begin{array}{l}\text { Distant latency (ms.) - sensory } \\
\text { fibers }\end{array}$} & Before treatment & $72,10 \%$ \\
\hline & & $1-4 \mathrm{M}$. & $67,00 \%$ \\
\hline & & 4-8 м. & $53,10 \%$ \\
\hline & \multirow{3}{*}{ Amplitude $(\boldsymbol{\mu V})$ - sensory fibers } & Before treatment & $91,50 \%$ \\
\hline & & $1-4 \mathrm{M.}$. & $87,70 \%$ \\
\hline & & 4-8 M. & $84,30 \%$ \\
\hline & \multirow{3}{*}{$\begin{array}{l}\text { Conduction velocity }(\mathrm{m} / \mathrm{s})-\mathrm{c} \\
\text { sensory fibers }\end{array}$} & Before treatment & $77,70 \%$ \\
\hline & & $1-4 \mathrm{M}$ & $89,80 \%$ \\
\hline & & $4-8 \mathrm{M}$. & $84,90 \%$ \\
\hline \multirow{9}{*}{$\begin{array}{l}\text { SSS } \\
\text { (symptom } \\
\text { severity scale) }\end{array}$} & \multirow{3}{*}{$\begin{array}{l}\text { Distant latency (ms.) - motor } \\
\text { fibers }\end{array}$} & Before treatment & $65,90 \%$ \\
\hline & & 1-4 м. & $58,70 \%$ \\
\hline & & $4-8 \mathrm{M}$. & $78,30 \%$ \\
\hline & \multirow{3}{*}{ Amplitude $(\mu V)$ - motor fibers } & Before treatment & $80,60 \%$ \\
\hline & & $1-4 \mathrm{M}$. & $86,90 \%$ \\
\hline & & 4-8 м. & $74,40 \%$ \\
\hline & \multirow{3}{*}{$\begin{array}{l}\text { Conduction velocity }(\mathrm{m} / \mathrm{s})- \\
\text { motor fibers }\end{array}$} & Before treatment & $79,00 \%$ \\
\hline & & $1-4 \mathrm{M}$ & $86,40 \%$ \\
\hline & & 4-8 м. & $81,90 \%$ \\
\hline
\end{tabular}

The subjective complaints are due not only to the damage to the sensory fibers, but also to the motor fibers of the n. medianus. Here again, the results show a high percentage of overlap in the different stages of the study - between $65.90 \%$ and $78.30 \%$ for distant latency between $74.40 \%$ and $86.90 \%$ for amplitude, and between $79.00 \%$ and $86,40 \%$ for the speed of conduction (Table 1)

Table 2 presents the results of the comparison between patients' self-assessments of change in FSS (functional status scale) function and objective ENG data. Again, there is a high percentage of comparability, both in the comparative analysis between FSS and motor fibers, and between FSS and sensory fibers.

The analysis of the results when comparing the FSS symptom severity assessment of the Boston Questionnaire and those obtained from ENG-study of motor fibers shows that among the FSSaverage values of the Boston questionnaire, those for distant latency-motor fibers from ENG-study the percentage of overlap ranged from $68.80 \%$ to $71.80 \%$ in the period before the start of treatment to 1-4 and 4-8 months after the start of treatment. Between FSS and the amplitude of ENG speed. Of conduction of motor fibers, this percentage varies between $86.10 \%$ and $93.20 \%$. 
Table 2. Comparison of BCTQ - FSS subjective assessment results (functional status scale) and the objective estimate measured by the ENG parameters of $n$. medianus.

\begin{tabular}{|c|c|c|c|}
\hline BCTQ & ENG-parameters of $n$. medianus & $\begin{array}{c}\text { Stage of } \\
\text { investigation }\end{array}$ & $\begin{array}{c}\% \text { of BCTQ and ENG } \\
\text { overlap }\end{array}$ \\
\hline \multirow{9}{*}{$\begin{array}{l}\text { FSS } \\
\text { (functional } \\
\text { status scale) }\end{array}$} & \multirow{3}{*}{$\begin{array}{l}\text { Distant latency (ms.) - motor } \\
\text { fibers }\end{array}$} & Before treatment & $71,80 \%$ \\
\hline & & $1-4 \mathrm{M}$. & $69,40 \%$ \\
\hline & & $4-8 \mathrm{M}$. & $68,80 \%$ \\
\hline & \multirow{3}{*}{ Amplitude $(\mu \mathrm{V})$ - motor fibers } & Before treatment & $83,20 \%$ \\
\hline & & $1-4 \mathrm{M.}$ & $93,20 \%$ \\
\hline & & $4-8 \mathrm{M.}$. & $86,10 \%$ \\
\hline & \multirow{3}{*}{$\begin{array}{l}\text { Conduction velocity }(\mathrm{m} / \mathrm{s})-\mathrm{c} \\
\text { motor fibers }\end{array}$} & Before treatment & $78,90 \%$ \\
\hline & & $1-4 \mathrm{M}$. & $82,10 \%$ \\
\hline & & $4-8 \mathrm{M.}$ & $95,60 \%$ \\
\hline \multirow{9}{*}{$\begin{array}{l}\text { FSS } \\
\text { (functional } \\
\text { status scale) }\end{array}$} & \multirow{3}{*}{$\begin{array}{l}\text { Distant latency (ms.) - sensory } \\
\text { fibers }\end{array}$} & Before treatment & $67,20 \%$ \\
\hline & & $1-4 \mathrm{M}$ & $64,70 \%$ \\
\hline & & $4-8 \mathrm{M}$. & $48,50 \%$ \\
\hline & \multirow{3}{*}{ Amplitude $(\mu V)$ - sensory fibers } & Before treatment & $91,70 \%$ \\
\hline & & $1-4 \mathrm{M}$. & $90,00 \%$ \\
\hline & & $4-8 \mathrm{M.}$ & $93,80 \%$ \\
\hline & \multirow{3}{*}{$\begin{array}{l}\text { Conduction velocity }(\mathrm{m} / \mathrm{s})- \\
\text { sensory fibers }\end{array}$} & Before treatment & $78,90 \%$ \\
\hline & & $1-4 \mathrm{M.}$ & $94,70 \%$ \\
\hline & & $4-8 \mathrm{~m}$. & $82,40 \%$ \\
\hline
\end{tabular}

We found that the degree of overlap between FSS and ENG sensory fibers was also significantly high. In the different stages of the study, the degree of overlap between the FSS and distant latency of sensory fibers averages varied between $48.50 \%$ and $67.20 \%$, for SNAP amplitude between $93.80 \%$ and $91.70 \%$, and for speed of conduction - between $78.90 \%$ and $95.60 \%$ (Table 2).

ANOVA analyzes of the $\eta$ coefficient show a high percentage of overlap in the results of the two instruments, which leads us to assume that the questionnaire we use is reliable in assessing the effect of physiotherapeutical treatment.

Comparative evaluation and comparison of results obtained from BCTQ and ENG study

Based on the ANOVA analysis and the calculation of the $\eta$ coefficient, we proved that there is no significant difference in the results obtained from the Boston questionnaire and those from the ENG examination. There is a high percentage of overlap - from $53.10 \%$ to $95.60 \%$.

Although the results of BCTQ are based on the subjective assessment of the patient, there is a high percentage of overlap with those of the objective study (ENG), which is a prerequisite for assuming that the questionnaire is highly reliable and valid and can be used as a tool for evaluating and analyzing a number of carpal tunnel studies, which is in line with Leite's findings that the Boston Questionnaire is highly reliable and can replace any other non-standard methods for assessing CTS severity [4]

Conclusions. In the presented facts of the discussion the impression makes the patient's influence both on the subjective complaints and the clinical symptoms as well as on the degree of restoration of the affected hand functions at the end of the physiotherapy course, the continuation of this trend up to 4 months after the end of the treatment and maintaining it for 4 to 8 months. The results obtained are determined by the proven prolonged action of the physiotherapeutical procedures included in the complex, electrophoresis, as well as the exercise program developed for the needs of the patients with CTS and its individualization according to the specific functional deficit and concomitant symptomatology in each patient.

There are many tools for assessing carpal tunnel syndrome - ENG, skin sensory testing, muscle strength testing and grip testing, assessment of the degree of subjective complaints, difficulties in daily professional activities. Many of the studies in the scientific literature concerning CTS problems have reported pain reduction and other symptoms and improvement in hand functions, but there are few tools where subjective results are well organized and easy to process and analyze [5].

In this line of thought, the literature has known a great deal of analysis and comparative studies related to the reliability of BCTQ, and most have identified it as more reliable in terms of 
diagnosis and severity of CTS than any other similar tool. The results of our analysis and comparison of the two Boston Questionnaire scales and the other tools used support all of these studies. According to many authors, the use of BCTQ is almost mandatory in the field of carpal tunnel syndrome $[4,5,6]$.

\section{REFERENCES}

1. Milanov I. (2009). Bolka v nevrologichnata praktika. Sofia: Meditsina i fizkultura.

2. Levine DW, et al. A self-administered questionnaire for the assessment of severity of symptoms and functional status in carpal tunnel syndrome. 1993; J Bone Joint Surg Am 75:1585-92

3. Dias, J. J., B. Bhowal, C. J. Wildin, J. R. Thompson. Assessing the outcome of disorders of the hand. Is the patient evaluation measure reliable, valid, responsive and without bias? - J Bone Joint Surg Br., 2001, 83(2): 235-240.

4. Leite JC, J., et al. A systematic review of the psychometric properties of the Boston Carpal Tunnel Questionnaire. 2008; BMC Musculoskelet Disord 78 (7)

5. Meirelles L.M. et al. Evalution of the Boston questionnaire applied at late post-operative period of carpal tunnel syndrome operated with the paine retinaculatome trhough palmar port. 2006; Acta ortop. bras. vol.14 no.3

6. Amadio R., Luchetti P. Carpal Tunnel Syndrome. 2007 Berlin Heidelberg New York Roma: Springer-Verlag. 